\title{
Breeding oilseed rape for pod shattering resistance
}

\author{
C. L. MORGAN ${ }^{1 *}$, Z. L. LADBROOKE ${ }^{1}$, D. M. BRUCE ${ }^{2}$, R. CHILD ${ }^{3}$ ANd A. E. ARTHUR ${ }^{1}$ \\ ${ }^{1}$ John Innes Centre, Norwich, NR4 7UH, UK \\ ${ }^{2}$ Silsoe Research Institute, Bedford, MK45 4HS, UK \\ ${ }^{3}$ Long Ashton Research Station, Bristol, BS18 9AF, UK
}

(Revised MS received 6 July 2000)

\begin{abstract}
SUMMARY
The genetic control of pod dehiscence was studied through the production, field trial and subsequent analysis of a full diallel involving seven parents selected for high and low resistance to pod shattering. Additive gene effects were most significant among the measures of pod shattering resistance with only minor contributions from non-additive gene effects. Genetic variation in measures of the stiffness of the pod wall were, however, determined by dominant gene effects. Genes for increased pod shattering resistance acted recessively. All characters showed high levels of heritability. Correlations among pod shatter resistance characters and other pod, raceme and plant characters were low suggesting that resistance is likely to be independent of other important agronomic traits.
\end{abstract}

\section{INTRODUCTION}

Oilseed rape (Brassica napus L.) is grown extensively in temperate zones throughout much of northern Europe, northern America and Asia. If it is compared to wheat, however, it is apparent that, in breeding terms, it is relatively undeveloped and in many aspects resembles a weed more than a cultivated crop (Thompson \& Hughes 1986). Pods which split easily to facilitate seed dispersal is one of these 'weedy' characters which is extremely detrimental to its use as a crop because considerable amounts of seed may be lost through seed shedding before and during harvest. Estimates of over $20 \%$ of the seed yield have been made for this loss (Price et al. 1996) though a typical figure is usually in the region of $10 \%$ (Kadkol et al. 1984). The value of the crop within the UK alone amounted to about $£ 420$ million p.a. for 1996 ; thus the loss of $10 \%$ amounts to $£ 42$ million p.a. (MAFF 1997). Potentially, therefore, increases in harvestable seed yield arising from reduced pod shattering will result in significant economic benefits. Additional benefits include the simplification of crop agronomy through the avoidance of swathing (cutting of the stand to promote premature drying), eliminating the use of desiccants, improving uniformity of the harvested seed and the reduction in seed contamination of the soil. This latter benefit is likely to be of

* To whom all correspondence should be addressed. Email: colin.morgan@bbsrc.ac.uk increasing importance as more genetically modified designer crops are grown and strict control measures are needed to avoid cross-contamination.

Little variation in resistance to pod shattering has been observed among existing genetic resources or cultivars of oilseed rape so the search for variation has been directed to a broader genetic base through the development of synthetic oilseed rape from wild genotypes of $B$. oleracea and B. rapa. This work has been described by Morgan et al. (1998) who also developed several methods of assessing the shatter resistance of individual pods and have also studied several plant, raceme and pod characters that might influence how this resistance is expressed within the crop canopy. Using these data Morgan et al. (1998) identified lines of synthetic rape which had significantly increased resistance to pod shattering. These synthetic lines, however, contained many agronomically deleterious traits including poor seed set and disease susceptibility that made them unsuitable as cultivars. Before attempting to transfer the characters which confer pod shatter resistance into new lines with suitable agronomic characters it is important to understand how these characters are genetically controlled. In this paper we describe the basis of this control through the analysis of the diallel crosses obtained among five lines of synthetic rape and two cultivars. These seven parental lines were selected because they represented a range of the expression of those characters believed to confer pod shattering resistance and also for a variety of other morphological traits. 


\section{MATERIALS AND METHODS}

\section{Plant material}

The five synthetic lines and two cultivars included in the diallel are described in Table 1 . They were chosen to represent a range of pod shattering resistance from no resistance (q28) to high resistance (dk142). These parents also differed in many other plant characters including plant height and branching, date of flowering, pod size, shape and angle.

Selfed seed collected from material grown in the field during 1997 was used to produce the parents for the diallel seed production. Seed was germinated in John Innes no. 1 compost and seedlings pricked out into John Innes no. 2 before vernalizing for 8 weeks at $6{ }^{\circ} \mathrm{C}$. The plants were subsequently grown in a glasshouse and bud pollination used to produce a full set of diallel crosses. All crosses were successful though some difficulty in producing selfed seed in lines $\mathrm{dk} 129$ and $\mathrm{dk} 142$ was noted. The $\mathrm{F}_{1}$ seed, including all crosses and parents, was then sown and vernalized as above and transplanted into the field in March 1998. Plants were grown at a spacing of $0.5 \mathrm{~m}$ within rows which were $1 \mathrm{~m}$ apart in two fully randomized blocks with five replicate plants per block giving a total of 490 plants. Standard agronomic treatments were applied to the trial to prevent pests and diseases at all growth stages including maturation of the pods. The trial was weeded by hand and irrigated when necessary. All plants were staked.

\section{Plant measurements}

Pod shattering resistance in a crop is likely to result from the combination of several plant characters including plant and raceme structures affecting canopy architecture, and pod characters affecting the strength of these pods. A range of characters was measured to assess these aspects of plant structure. Date of flowering, taken as the number of days after the first plant to flower (i.e. 22 April 1998), was recorded during development while just before maturity plant height, basal stem thickness and number of primary branches were recorded for all plants. At maturity a subjective visual and tactile assessment was made of pod shattering resistance of the field grown pods to provide a field score of 0 (very shatter susceptible pods) to 5 (extremely shatter resistant pods). After field assessment the terminal raceme was harvested from each plant and stored in the laboratory. Pod density was determined on each raceme after which five typical pods from the middle of the raceme were cut off and pod length and depth, beak length and pod and pedicel angles were measured using a graphics tablet and these data used to estimate raceme width. Mean, minimum and maximum pod wall thicknesses were estimated on one valve (taken at random) per pod using a 'Hall effect' measuring system. In this the pod valve was placed between a fixed and a movable pin which recorded the wall thickness as the pod was drawn between them. The output from the device was recorded on a virtual oscilloscope for analysis. Seed number per pod and mean seed dry weight were then determined on the combined sample of five pods.

Samples of five single mature pods were also harvested and equilibrated to constant humidity before measurement in tensile separation tests (Morgan et al. 1998). In these tests the abaxial surface of single pods were glued to a wooden base and the adaxial surface connected to a universal test machine (Davies \& Bruce 1997). A steadily increasing force was applied to these pods and a graph was plotted of force against time from the initiation of the force through dehiscence and then until relaxation of the pod. Results obtained through the tensile separation tests measure pod attributes affecting dehiscence: peak load measures the force required to make the initial crack at the pedicel end of the pod between the uppermost valve and the replum (as pods naturally dehisce in the field) and is a measure of the strength of the main vascular strand entering the pod and of cell

Table 1. Material used in diallel analysis

\begin{tabular}{|c|c|c|}
\hline Line & Derivation of material & Expected resistance \\
\hline $\mathrm{q} 28^{*}$ & Tapidor $\dagger \times\left(B\right.$. oleracea atlantica $\times$ B. rapa ' $\left.29^{\prime}\right) \neq$ & 1 \\
\hline $\mathrm{z} 79 *$ & Tapidor $\dagger \times($ B. oleracea macrocarpa $\times$ B. rapa ' 29 ' $) \neq$ & $1 \cdot 5$ \\
\hline $\mathrm{dk} 129 *$ & (B. rapa chinensis $\times$ B. oleracea alboglabra) $\$ \times \mathrm{N}-\mathrm{O}-109 \S$ & 3 \\
\hline $\mathrm{dk} 142 *$ & $\mathrm{~N}-\mathrm{O}-109 \S \times($ B. rapa chinensis $\times$ B. oleracea alboglabra $)$ & 4 \\
\hline $\mathrm{dk} 150^{*}$ & $\mathrm{~N}-\mathrm{O}-109 \S \times($ B. rapa chinensis $\times$ B. oleracea alboglabra $)$ & 2 \\
\hline Apex & Cultivar & 2 \\
\hline Tapidor & Cultivar & $1 \cdot 5$ \\
\hline
\end{tabular}

* Doubled haploid B. napus line.

$\dagger$ Doubled haploid B. napus cultivar.

* Synthetic B. napus.

$\S$ B. napus breeding line. 


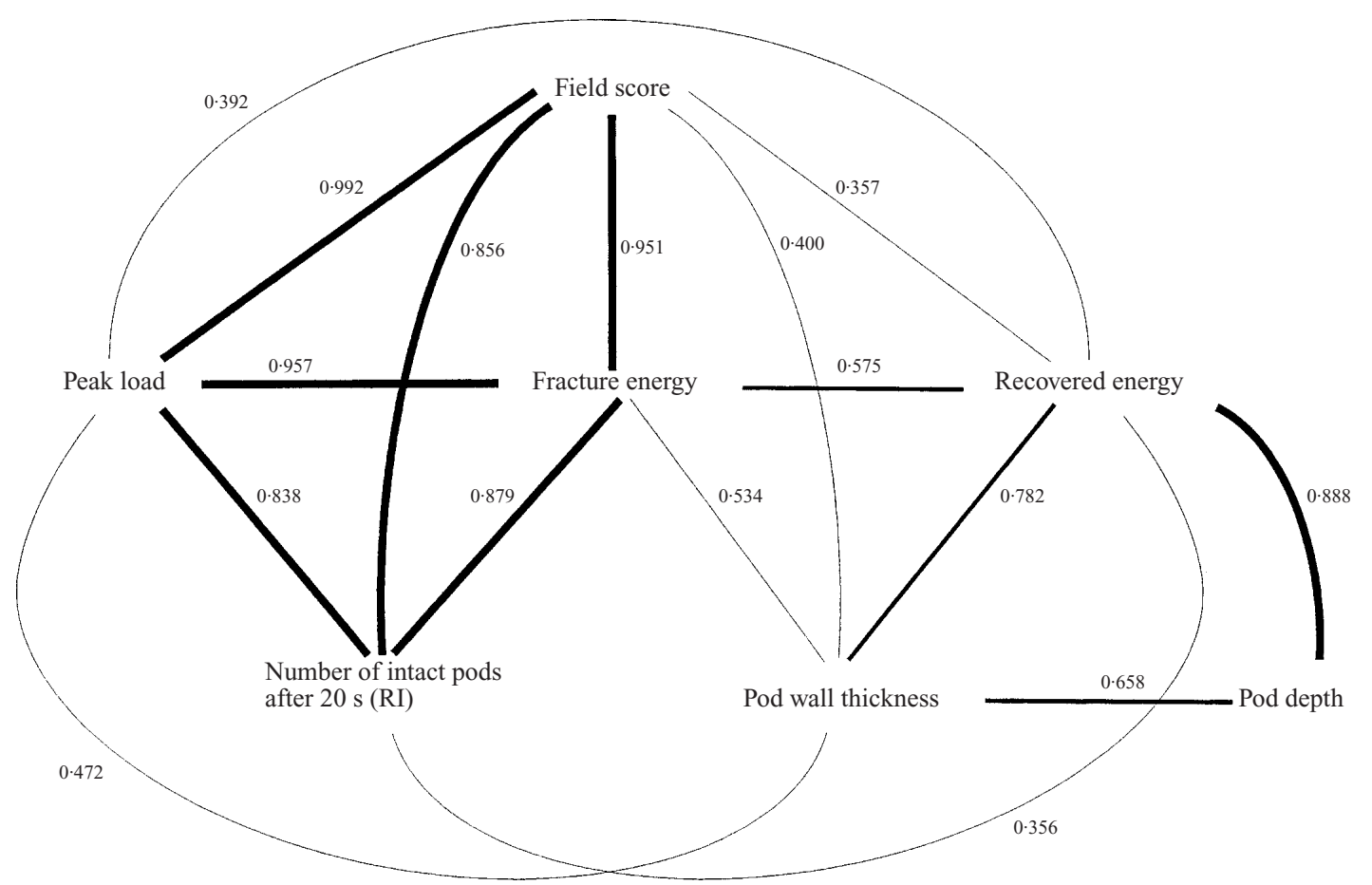

Fig. 1. Diagram illustrating the relationships among selected characters associated with pod shattering resistance as determined by their correlation coefficients (D.F. $=47$ ). All are significant at $P<0 \cdot 001$. Width of lines indicates value of coefficient of determination $\left(r^{2}\right):>70 \% ;-30-69 \% ;-<30 \%$.

adherence within the dehiscence zone. Fracture energy measures the total energy needed to initiate this crack and to propagate it along the valve-replum interface and is thus a measure of the toughness of the dehiscence zone (both cell adherence and width of the zone are accounted for in its calculation) and any vascular tissue running through this zone. Recovered energy characterizes the restoration of the deformed pod valve to its initial shape after tension is released and thus will be affected by the material of the pod wall (conferring stiffness), pod wall thickness and the curvature of the pod. This last is defined by the crosssectional shape of the valve and greater stiffness is likely to be found in deeper cupped u-shaped valves.

Also at maturity one sample of 20 individual pods was harvested from the five replicate plants within each block. These were equilibrated to constant humidity as described above, and used to assess the pod shattering resistance characteristics of the sample by being subjected to shaking in a drum with ball bearings. In this laboratory based, random impact test procedure the number of pods left intact after $20 \mathrm{~s}$ of standardized shaking in a drum with ball bearings was counted. This test measures the effect of an accumulation of impacts occurring randomly on the pod in contrast to the tensile separation tests which measures the force applied to a specific point, the pedicel end. The random impact tests will therefore differ from the tensile separation tests in being affected by other pod attributes such as pod length and width and any specific weaknesses such as between the beak and the pod valves. Field shatter score is a subjective assessment of overall pod strength under field conditions and is likely to be more affected by environmental conditions.

\section{Statistical analysis}

Preliminary analyses were carried out using individual families (D.F. $=48)$ and blocks (D.F. $=1$ ) as main effects tested against the amongst replicate plant error (D.F. $=392$ ). Subsequent analyses were carried out to estimate male and female effects (D.F. $=6$ ) and male $\times$ female interaction (D.F. $=35$ ) for which the error term included all other interactions (i.e. blocks $\times$ males, blocks $\times$ females and blocks $\times$ males $\times$ females; D.F. $=392$ ). Expected mean squares were used to calculate the components of variation from these analyses from which the proportions of the variation attributable to genetic components were estimated. It was noted that values of $\sigma_{\text {s }}^{2}$ $\left(\sigma_{\text {male }}^{2}+\sigma_{\text {female }}^{2}+\sigma_{\text {male.female }}^{2}\right)$ were highly correlated with $\sigma_{\text {family }}^{2}$ obtained from the analysis of 
family $\times$ block $(b=+0.916 ; r=+0.931)$ but were, on average $31 \%$ higher. These apparently higher values of $\sigma_{\mathrm{g}}^{2}$ resulted from the removal of block effects and interactions from the error term in the second analysis. The values of $\sigma_{\mathrm{g}}^{2}$ derived from the male $\times$ female analyses were subdivided into $\sigma_{\text {male }}^{2}+\sigma_{\text {female }}^{2}$ and $\sigma_{\text {male.female }}^{2}$ which were equated with general combining ability (GCA) and specific combining abilities (SCA) respectively.

Five of the traits used to characterize pod shattering resistance were considered for more detailed studies. These included: field shatter score - the basic trait on which the selection of parents in the formation of the diallel was based-and four of the laboratory measures of characters used to assess the trait: the number of pods intact after $20 \mathrm{~s}$ from the random impact tests (ip20), the energy needed to cause fracture of the dehiscence zone (fracture energy) and the maximum force needed to initiate dehiscence (peak load) in the tensile separation tests, and the energy recovered from the pods after dehiscence had been achieved. Using the means of the parental arrays in the diallel table, correlation coefficients were calculated among these characters (Fig. 1). Because peak load and fracture energy were very highly correlated and also behaved similarly in further analysis of genetic behaviour, only fracture energy was selected for the subsequent detailed description.

Analysis of variance of the diallel table (Hayman 1954) gave estimates of additive and non-additive gene effects. For these analyses the means of the five replicated plants within each block were used to provide two replicate blocks for this diallel analysis; however, missing experimental plants gave rise to some missing cells within the blocks. To provide a complete data set for the analysis, the data from reciprocal crosses were combined to provide two complete blocks for half diallel analysis. Combining reciprocal data is only valid if there are no maternal, reciprocal effects. These effects were tested for by analysing flowering date, plant height and number of primary branches, characters for which a single matrix with no missing cells was available. The full diallel analysis of these characters showed no reciprocal effects (c) and on this basis it was decided to proceed with the analysis of the half diallel for the selected characters. The error mean square from the family $x$ block analysis of variance, estimating plant to plant variation, was used to provide the tests of significance within the subsequent diallel analyses. Additivity in breeding terms may be equated to narrow sense heritability (also called general combining ability) while broad sense heritability (also called specific combining ability) will also include dominant gene effects. Plots of $\mathrm{W}_{\mathrm{r}}$ against $\mathrm{V}_{\mathrm{r}}$ were used to test the validity of the Hayman analysis while plots of each hybrid on the mean value for their parents gave information of general and specific combining ability (additivity and dominance) with respect to individual hybrid families. All analyses of variance, regressions and the Hayman analyses were carried out using the statistical package GENSTAT 5 (Genstat 1987).

\section{RESULTS}

Parents

Significant variation among the parents was observed for all the characters measured (Table 2). In general there was about a twofold variation between the most extreme parents for any given character except those relating directly to the measurement of pod shattering resistance where the difference was between five and tenfold. The cultivars, Apex and Tapidor, were characterized by long, horizontal pods resulting in wide racemes in contrast to the pod shatter resistant lines $\mathrm{dk} 129$ and $\mathrm{dk} 142$ which had shorter, more upright pods. Pod length was associated with seed number per pod though $\mathrm{dk} 150$ and especially $\mathrm{dk} 142$ had many fewer seeds than expected. There are several possible explanations, not mutually exclusive, for these differences in seed set which include: possible chromosomal rearrangements or deletions following the initial synthesis of the two diploid parent genomes, changes in floral development resulting in late anther dehiscence and poor pollen production, the expression of self incompatibility genes (SI) within the genome arising from the synthetic $B$. rapa chinensis $\times B$. oleracea alboglabra (Parkin 1995) and the failure of the enzyme polygalacturonase to cause anther dehiscence (Petersen et al. 1996). This enzyme is also associated with pod dehiscence and consequently a pleiotropic linkage between the two similar physiological processes may have resulted in combining resistance to pod shattering with increased sterility and poor seed set. There was no relationship of seed set with mean seed weight. Line dk129 differed significantly from the other lines, including dk142, in having deeper pods with thicker walls, features reflected in the energy recovered from the elasticity of the pod wall measured in the tensile separation tests. The most compliant pods were those of $\mathrm{dk} 129$ which retained over four times the recovered energy of the stiffest pods dk150, q28 and Tapidor, with Apex and z79 intermediate for this character.

Parental lines performed as expected for field shatter resistance score such that $\mathrm{dk} 142$ was noticeably the most shatter resistant closely followed by dk129. At the other end of the scale q28 had considerably weaker pods. The other parents were intermediate for this character (Table 2). Random impact tests confirmed parent $\mathrm{dk} 142$ as the most resistant line though dk129 was similar to the cultivars which appeared relatively shatter resistant compared to the field estimates. As with the field scores q28 was the least resistant followed by z79. Both peak load and 
Table 2. Parental means

\begin{tabular}{lrrrrrrrr}
\hline \hline & $\mathrm{q} 28$ & $\mathrm{z} 79$ & $\mathrm{dk} 129$ & $\mathrm{dk} 142$ & $\mathrm{dk} 150$ & Apex & Tapidor & S.E. ${ }^{*}$ \\
\hline Number of days to first flower (after 22 April) & $4 \cdot 0$ & $23 \cdot 3$ & $12 \cdot 8$ & $12 \cdot 7$ & $14 \cdot 4$ & $20 \cdot 4$ & $18 \cdot 9$ & $0 \cdot 96$ \\
Plant height (cm) & $96 \cdot 4$ & $107 \cdot 6$ & $161 \cdot 6$ & $139 \cdot 9$ & $140 \cdot 9$ & $130 \cdot 3$ & $131 \cdot 6$ & $4 \cdot 50$ \\
Stem thickness (cm) & $11 \cdot 5$ & $10 \cdot 7$ & $15 \cdot 3$ & $19 \cdot 2$ & $18 \cdot 5$ & $15 \cdot 6$ & $16 \cdot 9$ & $1 \cdot 22$ \\
Number of primary branches & $5 \cdot 8$ & $5 \cdot 0$ & $5 \cdot 5$ & $6 \cdot 2$ & $6 \cdot 5$ & $7 \cdot 6$ & $5 \cdot 4$ & $0 \cdot 42$ \\
Pod length (mm) & $38 \cdot 8$ & $38 \cdot 7$ & $42 \cdot 9$ & $37 \cdot 9$ & $45 \cdot 8$ & $62 \cdot 6$ & $65 \cdot 7$ & $2 \cdot 28$ \\
Beak length (mm) & $18 \cdot 6$ & $10 \cdot 8$ & $9 \cdot 9$ & $14 \cdot 6$ & $11 \cdot 0$ & $14 \cdot 4$ & $14 \cdot 4$ & $0 \cdot 61$ \\
Angle of pod to rachis ( ${ }^{\circ}$ & $36 \cdot 4$ & $61 \cdot 4$ & $29 \cdot 7$ & $27 \cdot 1$ & $32 \cdot 1$ & $68 \cdot 9$ & $68 \cdot 3$ & $2 \cdot 83$ \\
Estimated raceme width (mm) & $108 \cdot 8$ & $118 \cdot 1$ & $86 \cdot 8$ & $76 \cdot 1$ & $93 \cdot 8$ & $180 \cdot 7$ & $178 \cdot 7$ & $6 \cdot 79$ \\
Pod density (per cm) & $1 \cdot 19$ & $1 \cdot 29$ & $0 \cdot 51$ & $0 \cdot 69$ & $0 \cdot 93$ & $1 \cdot 03$ & $1 \cdot 14$ & $0 \cdot 06$ \\
Number of seeds per pod & $12 \cdot 8$ & $10 \cdot 3$ & $10 \cdot 4$ & $4 \cdot 6$ & $8 \cdot 9$ & $23 \cdot 2$ & $23 \cdot 2$ & $1 \cdot 32$ \\
Mean seed weight (mg) & $3 \cdot 2$ & $3 \cdot 5$ & $5 \cdot 6$ & $3 \cdot 4$ & $3 \cdot 9$ & $4 \cdot 9$ & $4 \cdot 1$ & $0 \cdot 22$ \\
Depth of pods (mm) & $4 \cdot 2$ & $4 \cdot 8$ & $6 \cdot 2$ & $3 \cdot 9$ & $3 \cdot 6$ & $4 \cdot 6$ & $4 \cdot 2$ & $0 \cdot 14$ \\
Mean pod wall thickness (mm) & $0 \cdot 45$ & $0 \cdot 52$ & $0 \cdot 62$ & $0 \cdot 51$ & $0 \cdot 42$ & $0 \cdot 33$ & $0 \cdot 31$ & $0 \cdot 018$ \\
Field score for pod shattering index $\dagger$ & $0 \cdot 01$ & $0 \cdot 98$ & $2 \cdot 05$ & $3 \cdot 74$ & $1 \cdot 00$ & $1 \cdot 10$ & $0 \cdot 90$ & $0 \cdot 158$ \\
Number pods intact after 20 seconds & $1 \cdot 50$ & $5 \cdot 00$ & $15 \cdot 50$ & $18 \cdot 08$ & $9 \cdot 00$ & $13 \cdot 00$ & $14 \cdot 00$ & $0 \cdot 950$ \\
Peak load (N) & $0 \cdot 74$ & $2 \cdot 64$ & $4 \cdot 77$ & $6 \cdot 00$ & $2 \cdot 05$ & $2 \cdot 73$ & $2 \cdot 15$ & $0 \cdot 275$ \\
Recovered energy (J) & $0 \cdot 18$ & $0 \cdot 28$ & $0 \cdot 66$ & $0 \cdot 20$ & $0 \cdot 15$ & $0 \cdot 34$ & $0 \cdot 16$ & $0 \cdot 031$ \\
Fracture energy (J) & $0 \cdot 09$ & $0 \cdot 29$ & $0 \cdot 88$ & $1 \cdot 04$ & $0 \cdot 32$ & $0 \cdot 38$ & $0 \cdot 27$ & $0 \cdot 054$ \\
\hline \hline
\end{tabular}

* S.E.s determined from error Ms derived from male $\times$ female ANOVA with 392 D.F.

$\dagger 0$, shatter susceptible; 4 , shatter resistant.

fracture energy measured in the tensile separation tests showed that the parents behaved in a similar way to that for field shatter score with large differences apparent between the pod shattering resistant $\mathrm{dk} 142$ and the sensitive line q28.

Date of flowering was earliest in q28 and latest in the cultivars and $\mathrm{z} 79$ while the dk lines (which included the shattering resistant types) were intermediate. Lines q28 and z79 were the smallest plants as assessed by plant height, stem thickness and number of branches. There were no consistent trends among the other lines for these characters so that $\mathrm{dk} 129$ was tallest, dk142 had the thickest stems and Apex had most primary branches.

\section{Field score for shattering resistance}

The analysis of variance revealed significant family and block effects (Table 3) though when $\sigma_{\text {block }}^{2}$ was estimated as a percentage, its contribution to the total variation was only $4 \%$. This block effect was thought to have arisen from changes in the weather which occurred between the two occasions when the blocks were measured and which took place over successive days; high humidity may have increased the dampness of the pods resulting in an apparent increased shatter resistance. This illustrates the problems of reproducibility that may arise when using field score as the sole method of assessing pod shatter resistance. There was, however, no family $\times$ block interaction as a consequence of this response to the environment. Variation among both male and female arrays was highly significant (Table 4). Additive gene effects $\left(\sigma_{\text {male }}^{2}+\sigma_{\text {female }}^{2}\right)$ were three times greater than the nonadditive component $\left(\sigma_{\text {male.female }}^{2}\right)$ at $58 \%$ and $19 \%$ respectively. Results from the Hayman analysis (Table 5) showed both strong additive and non-additive gene effects with a dominance (b): additivity ratio (a) $\left(\sqrt{ }\left(\mathrm{H}_{1} / \mathrm{D}\right)\right)$ of $0 \cdot 58$. The dominance (b) contribution to the genetic variation showed significant directional $\left(b_{1}\right)$ and ambi-directional $\left(b_{2}\right)$ components. The reasons for the presence of both these components can be seen in the graph of the relationship between $\mathrm{W}_{\mathrm{r}}$ and $\mathrm{V}_{\mathrm{r}}$ (Fig. $2 a$ ). The regression line did not differ significantly from 1 and lies midway between the $1: 1$ line and the parabola suggesting the presence of both additive and non-additive components. Line dk142 had the highest values of $\mathrm{W}_{\mathrm{r}}$ and $\mathrm{V}_{\mathrm{r}}$ and was the main determinant of $b_{1}$ while the close proximity of the other arrays accounts for the significance of $b_{2}$.

The relationship between genetic and phenotypic aspects of the variation are explored in Fig. $2 a$ in which the standardized total mean squares of the array variance and covariance are plotted against the standardized pod shatter scores (data were standardized as $(\overline{\mathrm{x}}-\mathrm{x}) / \sigma^{2}$. The two shatter resistant lines appear to behave differently in that the high pod shatter resistance in $\mathrm{dk} 142$ results from the presence of recessive genes whereas the slightly lower resistance of $\mathrm{dk} 129$ appears to depend on moderate dominant gene effects. The other crosses, especially q28, appear to have dominant genes for shattering sensitivity. Fig. $4 a$ shows the relative position of the individual hybrids (cells in the Hayman analysis matrix) as a function of the mean of both parents. The slope of the line is equivalent to additivity (a) in the Hayman 
Table 3. Analysis of variance for all characters

\begin{tabular}{|c|c|c|c|c|c|c|c|c|}
\hline \multirow[b]{3}{*}{ Character } & \multicolumn{4}{|c|}{ Mean squares from ANOVA } & & & & \\
\hline & \multirow{2}{*}{$\begin{array}{c}\text { Between } \\
\text { families } \\
\text { (D.F. }=48)\end{array}$} & \multirow{2}{*}{$\begin{array}{l}\text { Between } \\
\text { blocks } \\
(\text { D.F. }=1)\end{array}$} & \multirow{2}{*}{$\begin{array}{c}\text { Families } \times \\
\text { Blocks } \\
(\text { D.F. }=48)\end{array}$} & \multirow{2}{*}{$\begin{array}{l}\text { Error mean } \\
\quad \text { square } \\
\text { (D.F. }=392)\end{array}$} & \multicolumn{4}{|c|}{ Component of variation $\%$} \\
\hline & & & & & $\left(\sigma_{\text {family }}^{2}\right)$ & $\left(\sigma_{\text {block }}^{2}\right)$ & $\left(\sigma_{\text {family.block }}^{2}\right)$ & $\left(\sigma^{2}\right)$ \\
\hline $\begin{array}{l}\text { Number of days to first flower } \\
\text { (after } 22 \text { April) }\end{array}$ & $138 \cdot 7 * * *$ & $15 \cdot 3$ & $19 \cdot 5^{* * *}$ & $8 \cdot 743$ & $52 \cdot 3$ & 0 & $9 \cdot 4$ & $38 \cdot 3$ \\
\hline Maximum plant height & $2056 \cdot 4 * * *$ & $2864 \cdot 7 * * *$ & $153 \cdot 4$ & $213 \cdot 6$ & $45 \cdot 1$ & $2 \cdot 6$ & 0 & $52 \cdot 3$ \\
\hline Stem thickness & $54 \cdot 1 * * *$ & $240 \cdot 5 * * *$ & $22 \cdot 0$ & $14 \cdot 4$ & $16 \cdot 1$ & $4 \cdot 5$ & $7 \cdot 6$ & 71.9 \\
\hline Number of primary branches & $5 \cdot 51^{* * *}$ & $13 \cdot 01^{* *}$ & $2 \cdot 01$ & 1.74 & $16 \cdot 0$ & $2 \cdot 1$ & $2 \cdot 5$ & $79 \cdot 4$ \\
\hline Pod length & $778 \cdot 7 * * *$ & $508 \cdot 8^{* * *}$ & $94 \cdot 0 * * *$ & $49 \cdot 5$ & $53 \cdot 3$ & $1 \cdot 3$ & $6 \cdot 9$ & $38 \cdot 5$ \\
\hline Beak length & $56 \cdot 56 * * *$ & 1.37 & $4 \cdot 14$ & 3.73 & $57 \cdot 9$ & 0 & $0 \cdot 9$ & $41 \cdot 2$ \\
\hline Angle of pod to rachis & $1497 \cdot 1 * * *$ & $101 \cdot 6$ & $89 \cdot 7$ & $80 \cdot 9$ & $63 \cdot 0$ & 0 & $0 \cdot 8$ & $36 \cdot 2$ \\
\hline Estimated raceme width & $8548 \cdot 9 * * *$ & $441 \cdot 2$ & $608 \cdot 7$ & $455 \cdot 1$ & $62 \cdot 0$ & 0 & $2 \cdot 4$ & $35 \cdot 6$ \\
\hline Pod density & $0 \cdot 232 * * *$ & $0 \cdot 041$ & $0.056^{*}$ & 0.036 & $30 \cdot 5$ & 0 & $6 \cdot 9$ & $62 \cdot 6$ \\
\hline Number of seeds per pod & $305 \cdot 0 * * *$ & $115 \cdot 7 * * *$ & $31 \cdot 4 * * *$ & $16 \cdot 3$ & $58 \cdot 2$ & $0 \cdot 7$ & $6 \cdot 4$ & $34 \cdot 7$ \\
\hline Mean seed weight & $3 \cdot 10^{* * *}$ & $0 \cdot 40$ & $0.84 * *$ & $0 \cdot 46$ & $29 \cdot 6$ & 0 & $10 \cdot 2$ & $60 \cdot 2$ \\
\hline Depth of pods & $2 \cdot 24 * * *$ & 0 & $0 \cdot 39 * * *$ & $0 \cdot 17$ & $46 \cdot 1$ & 0 & $11 \cdot 0$ & $42 \cdot 9$ \\
\hline Mean pod wall thickness & $6 \cdot 08 * * *$ & 0.53 & $0 \cdot 50$ & $0 \cdot 33$ & $60 \cdot 6$ & 0 & $3 \cdot 7$ & $35 \cdot 7$ \\
\hline Field score for pod shattering index & $3 \cdot 87^{* * *}$ & $6 \cdot 25^{* * *}$ & $0 \cdot 32$ & $0 \cdot 25$ & $55 \cdot 4$ & $3 \cdot 8$ & $2 \cdot 3$ & $38 \cdot 5$ \\
\hline Number pods intact after 20 seconds & $55 \cdot 35 * * *$ & - & - & $8.84 \dagger$ & $72 \cdot 5$ & - & - & $27 \cdot 5$ \\
\hline Peak load & $12 \cdot 88^{* * *}$ & $0 \cdot 44$ & 1.76 & $0 \cdot 65$ & $56 \cdot 1$ & 0 & $11 \cdot 3$ & $32 \cdot 6$ \\
\hline Fracture energy & $0 \cdot 477 * * *$ & $0 \cdot 162 *$ & $0.038 * *$ & $0 \cdot 028$ & $53 \cdot 5$ & $0 \cdot 6$ & $11 \cdot 4$ & $34 \cdot 5$ \\
\hline Recovered energy & $0 \cdot 113 * * *$ & $0 \cdot 201 * * *$ & $0 \cdot 034 * * *$ & $0 \cdot 007$ & $37 \cdot 9$ & $3 \cdot 3$ & $25 \cdot 6$ & $33 \cdot 2$ \\
\hline
\end{tabular}

$\dagger$ Error MS $=49$ D.F. ${ }^{* * *}, P<0 \cdot 001 ;{ }^{* *}, P=0 \cdot 01-0 \cdot 001 ; *, P=0 \cdot 05-0 \cdot 01$. 
Table 4. Analysis of variance for all characters

\begin{tabular}{|c|c|c|c|c|c|c|c|c|}
\hline \multirow[b]{3}{*}{ Character } & \multicolumn{4}{|c|}{ Mean squares from ANOVA } & & & & \\
\hline & \multirow{2}{*}{$\begin{array}{c}\text { Between } \\
\text { males } \\
(\text { D.F. }=6)\end{array}$} & \multirow{2}{*}{$\begin{array}{c}\text { Between } \\
\text { females } \\
(\text { (D.F. = 6) }\end{array}$} & \multirow{2}{*}{$\begin{array}{c}\text { Males } \times \\
\text { Females } \\
(\text { D.F. }=36)\end{array}$} & \multirow{2}{*}{$\begin{array}{l}\text { Error mean } \\
\quad \text { square } \\
\text { (D.F. }=392 \text { ) }\end{array}$} & \multicolumn{4}{|c|}{ Component of variation $\%$} \\
\hline & & & & & $\left(\sigma_{\text {males }}^{2}\right)$ & $\left(\sigma_{\text {females }}^{2}\right)$ & $\left(\sigma_{\text {males.females }}^{2}\right)$ & $\left(\sigma^{2}\right)$ \\
\hline Number of days to first flower & $387 \cdot 89$ & $584 \cdot 75$ & $32 \cdot 26$ & $9 \cdot 19$ & $25 \cdot 6$ & $39 \cdot 7$ & $11 \cdot 6$ & $23 \cdot 1$ \\
\hline Plant height & $7466 \cdot 6$ & $3616 \cdot 4$ & $888 \cdot 7$ & $202 \cdot 5$ & $31 \cdot 0$ & $12 \cdot 9$ & $22 \cdot 7$ & $33 \cdot 4$ \\
\hline Stem thickness & $166 \cdot 44$ & $61 \cdot 20$ & $39 \cdot 54$ & $14 \cdot 81$ & $14 \cdot 7$ & $2 \cdot 5$ & $20 \cdot 1$ & $60 \cdot 2$ \\
\hline Number of primary branches & $8 \cdot 228$ & $8 \cdot 870$ & $4 \cdot 704$ & $1 \cdot 737$ & $4 \cdot 0$ & $4 \cdot 7$ & $23 \cdot 3$ & $68 \cdot 1$ \\
\hline Pod length & $1377 \cdot 21$ & $2886 \cdot 43$ & $304 \cdot 39$ & 51.94 & $14 \cdot 8$ & $35 \cdot 7$ & $24 \cdot 4$ & $25 \cdot 1$ \\
\hline Beak length & $183 \cdot 83$ & $181 \cdot 32$ & $14 \cdot 78$ & 3.66 & $31 \cdot 2$ & $30 \cdot 8$ & $14 \cdot 4$ & $23 \cdot 7$ \\
\hline Angle of pod to rachis & $4486 \cdot 98$ & $5074 \cdot 41$ & $344 \cdot 03$ & $79 \cdot 92$ & $30 \cdot 6$ & $35 \cdot 0$ & $13 \cdot 7$ & $20 \cdot 7$ \\
\hline Estimated raceme width & $21755 \cdot 2$ & $33589 \cdot 5$ & $1958 \cdot 3$ & $460 \cdot 6$ & $25 \cdot 4$ & $40 \cdot 5$ & $13 \cdot 4$ & $20 \cdot 7$ \\
\hline Pod density & $0 \cdot 571$ & $0 \cdot 377$ & $0 \cdot 178$ & 0.035 & $27 \cdot 8$ & $17 \cdot 4$ & $9 \cdot 6$ & $45 \cdot 2$ \\
\hline Number of seeds per pod & $648 \cdot 03$ & $1228 \cdot 46$ & $91 \cdot 44$ & $17 \cdot 26$ & $19 \cdot 8$ & $40 \cdot 4$ & $18 \cdot 4$ & $21 \cdot 4$ \\
\hline Mean seed weight & $6 \cdot 219$ & $9 \cdot 944$ & $1 \cdot 393$ & $0 \cdot 482$ & $13 \cdot 2$ & $23 \cdot 3$ & $17 \cdot 4$ & $46 \cdot 1$ \\
\hline Depth of pods (mean of pods) & $5 \cdot 475$ & $8 \cdot 592$ & $0 \cdot 626$ & $0 \cdot 186$ & $21 \cdot 6$ & $35 \cdot 5$ & $13 \cdot 7$ & $29 \cdot 1$ \\
\hline Mean pod wall thickness $\left(\times 10^{3}\right)$ & $2 \cdot 122$ & $2 \cdot 112$ & $0 \cdot 100$ & $0 \cdot 034$ & $35 \cdot 7$ & $35 \cdot 5$ & $8 \cdot 3$ & $20 \cdot 6$ \\
\hline Field score for pod shattering index & $12 \cdot 278$ & $11 \cdot 310$ & $1 \cdot 231$ & $0 \cdot 249 \dagger$ & $30 \cdot 1$ & $27 \cdot 5$ & $18 \cdot 7$ & $23 \cdot 7$ \\
\hline Number pods intact after 20 seconds & $199 \cdot 15$ & $174 \cdot 34$ & $12 \cdot 64^{\mathrm{Ns}}$ & $9 \cdot 03$ & $42 \cdot 7$ & $37 \cdot 0$ & $5 \cdot 8$ & $14 \cdot 5$ \\
\hline Peak load & $36 \cdot 156$ & $52 \cdot 120$ & $2 \cdot 853$ & $0 \cdot 755$ & $26 \cdot 9$ & $39 \cdot 8$ & 11.9 & $21 \cdot 4$ \\
\hline Fracture energy & $1 \cdot 4052$ & 1.9342 & 0.0918 & $0 \cdot 0288$ & $28 \cdot 5$ & $40 \cdot 0$ & $9 \cdot 6$ & 21.9 \\
\hline Recovered energy & $0 \cdot 2339$ & $0 \cdot 3578$ & $0 \cdot 0549$ & 0.0095 & $15 \cdot 8$ & $26 \cdot 7$ & $28 \cdot 0$ & $29 \cdot 4$ \\
\hline
\end{tabular}

$\dagger$ Error MS $=49$ D.F.; all MS are significant to $P<0.001$ except where indicated. 


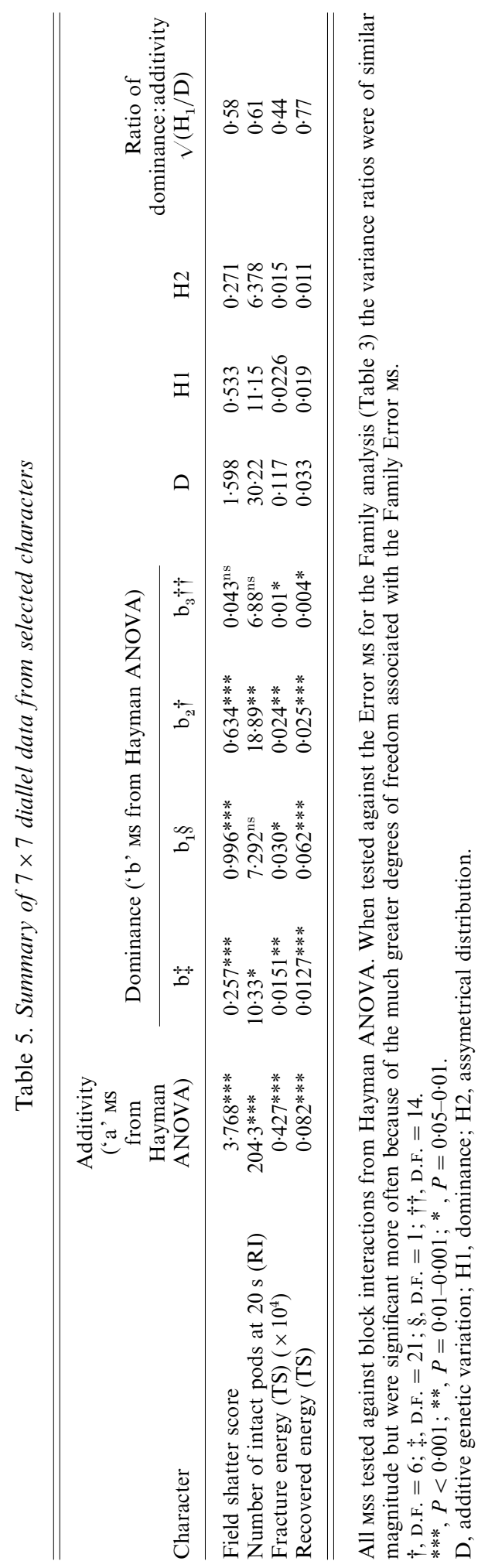

analysis or $\sigma_{\text {male }}^{2}+\sigma_{\text {female }}^{2}$ in the male $\times$ female analysis of variance. The slope of the fitted regression is less than 1 indicating the presence of non-additive effects (SCA or dominance). The slope is determined chiefly through the hybrids derived from dk129 and dk142 being below the line which also indicates the recessiveness of the character thus affirming the results from the Hayman analysis.

\section{Random impact data-number of pods intact after $20 \mathrm{~s}$}

There were significant differences among families (Table 3) but the absence of replicate data within the blocks did not allow block effects to be estimated. Again, male and female effects were highly significant though there were no male $\times$ female interactions. Additive gene effects $\left(\sigma_{\text {male }}^{2}+\sigma_{\text {female }}^{2}\right)$ were very high $(80 \%)$ in contrast to non-additive gene effects $\left(\sigma_{\text {male.female }}^{2}\right)$ which were very low $(6 \%)$. As with field shatter score, the genetic component $\left(\sigma_{\mathrm{g}}^{2}\right)$ was higher than that derived from the analysis of the families. In the Hayman analysis additive gene action was highly significant but non-additive effects were low and ambidirectional $\left(b_{2}\right)$. The dominance ratio of 0.61 was similar to that of field shatter score. This lack of dominance was also seen in the proximity of the regression line close to the parabola and with a slope which did not differ significantly from 1 . It is also seen in the absence of a clear pattern in the distribution of the points in Fig. $3 b$. A slope of unity in Fig. $4 b$ again shows the additive nature of the genetic control and the absence of points departing from the line also confirms the lack of dominant gene effects.

\section{Tensile separation tests - fracture energy}

Here, there was a significant family $\times$ block interaction (Table 3), and to a lesser extent block effects. However, as before, these effects were small compared to the family effect and error; thus $\sigma_{\text {family }}^{2}$ accounted for $54 \%$ of the variation while $\sigma_{\text {family.block }}^{2}$ was only $11 \%$. Variation amongst male and female arrays was again very large with no male $\times$ female interaction. Total variation due to genetic factors $\left(\sigma_{\mathrm{g}}^{2}\right)$ was very high $(69 \%)$ with a contribution of $10 \%$ from dominant gene effects $\left(\sigma_{\text {male.female }}^{2}\right)$ to $\sigma_{\mathrm{g}}^{2}$. In the Hayman analysis dominance was significant and was partitioned jointly between directional $\left(b_{1}\right)$ and ambidirectional $\left(b_{2}\right)$ effects. The dominance ratio was, however, low $(0 \cdot 44)$ as could be seen from the closeness of the fitted regression line to the parabola in Fig. $2 c$. As with the field score, the small amount of dominance was for shattering susceptibility in all the lines except those derived from $\mathrm{dk} 142$ and $\mathrm{dk} 129$ (Fig. 3c). When the hybrid values were plotted against the mean of their parents (Fig. 4c) the fitted regression showed a 

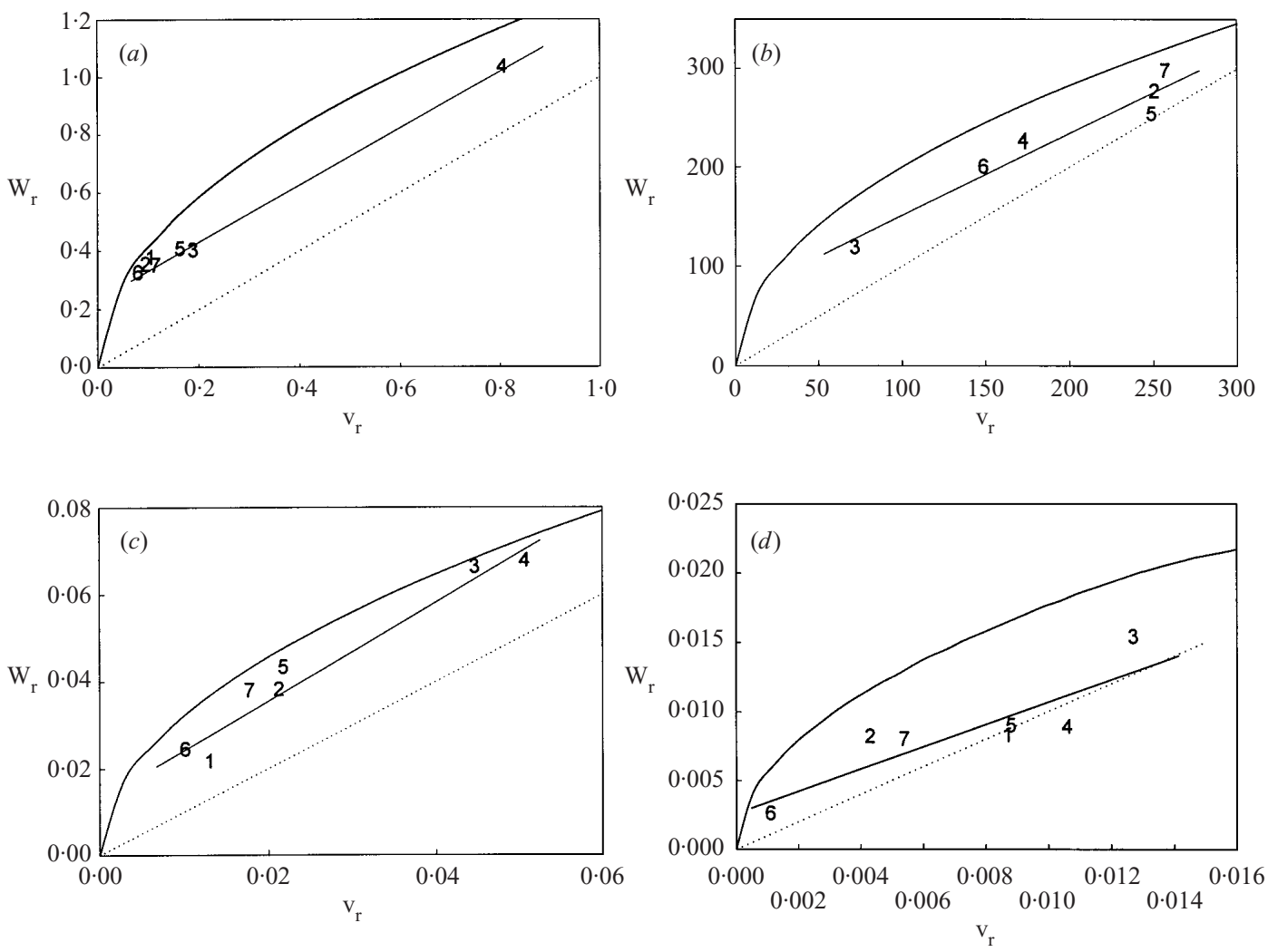

Fig. 2. Relationship between the variance of the offspring for each parental line $\left(\mathrm{V}_{\mathrm{r}}\right)$ and their covariance with the recurring parent $\left(\mathrm{W}_{\mathrm{r}}\right)$. (a) Mean pod wall thickness; $(b)$ field pod shatter score; $(c)$ number of intact pods after $20 \mathrm{~s}$ random impact; $(d)$ pod fracture energy (tensile separation). The parabola defines the theoretical limit to the $\mathrm{W}_{\mathrm{r}}: \mathrm{V}_{\mathrm{r}}$ ratio (calculated from $\mathrm{W}_{\mathrm{r}}^{2}=\mathrm{V}_{\mathrm{r}} \times \mathrm{V}_{\mathrm{p}}$; where $\mathrm{V}_{\mathrm{p}}$ is the variance of the parents). Points lying on the $1: 1$ line indicate full dominance for that character while points lying on the parabola indicate absence of dominance. Lines are: 1 . q28; 2. z79; 3. dk129; 4. dk142; 5. dk150; 6. Apex; 7. Tapidor.

significant but small decrease in slope confirming the presence of low dominance for the shatter susceptible character. Interestingly, the points in the regression can be split into three groups; those showing low resistance including lines q28 and z79; those showing higher resistance including hybrids derived from dk142 and dk129 and the single hybrid between dk142 and dk129 which had the highest resistance of all.

\section{Recovered energy}

There were highly significant differences among the families (Table 3 ) but these were complicated by the presence of significant family $\times$ block interactions which accounted for over $26 \%$ of the total variation compared to only $38 \%$ accounted for by family effects. The reason for this was not clear. As with the other three characters described above there were highly significant male and female effects but for this character the male $\times$ female interaction was largest giving estimates of $28 \%$ for dominance effects $\left(\sigma_{\text {male.female }}^{2}\right)$ compared to $44 \%$ for additive effects $\left(\sigma_{\text {male }}^{2}+\sigma_{\text {female }}^{2}\right)$. These results were reflected in the significant values of both a (additivity) and $b_{1}$ and $b_{2}$ (dominance) in the Hayman analysis and the high dominance ratio of $0 \cdot 77$. The closeness of the regression to the $1: 1$ line in Fig. $2 d$ also indicates the presence of dominance gene effects. Plotting the genotypic against the phenotypic expression of this character shown in Fig. $3 d$ shows that the stiffness of the pod wall in dk129 is essentially a recessive character, though Apex, intermediate in this respect, shows dominance. This provides evidence of independent gene action for several possible mechanisms postulated for this trait i.e. pod wall thickness, elasticity of the wall material and the cross-sectional shape of the pod valve. Expressing the results for the mean pod wall thickness and pod depth in a similar way (graph not shown) indicates that there is little dominance for these effects; thus additive gene action may be the major component in determining these results. Of these four characters, the slope of the 

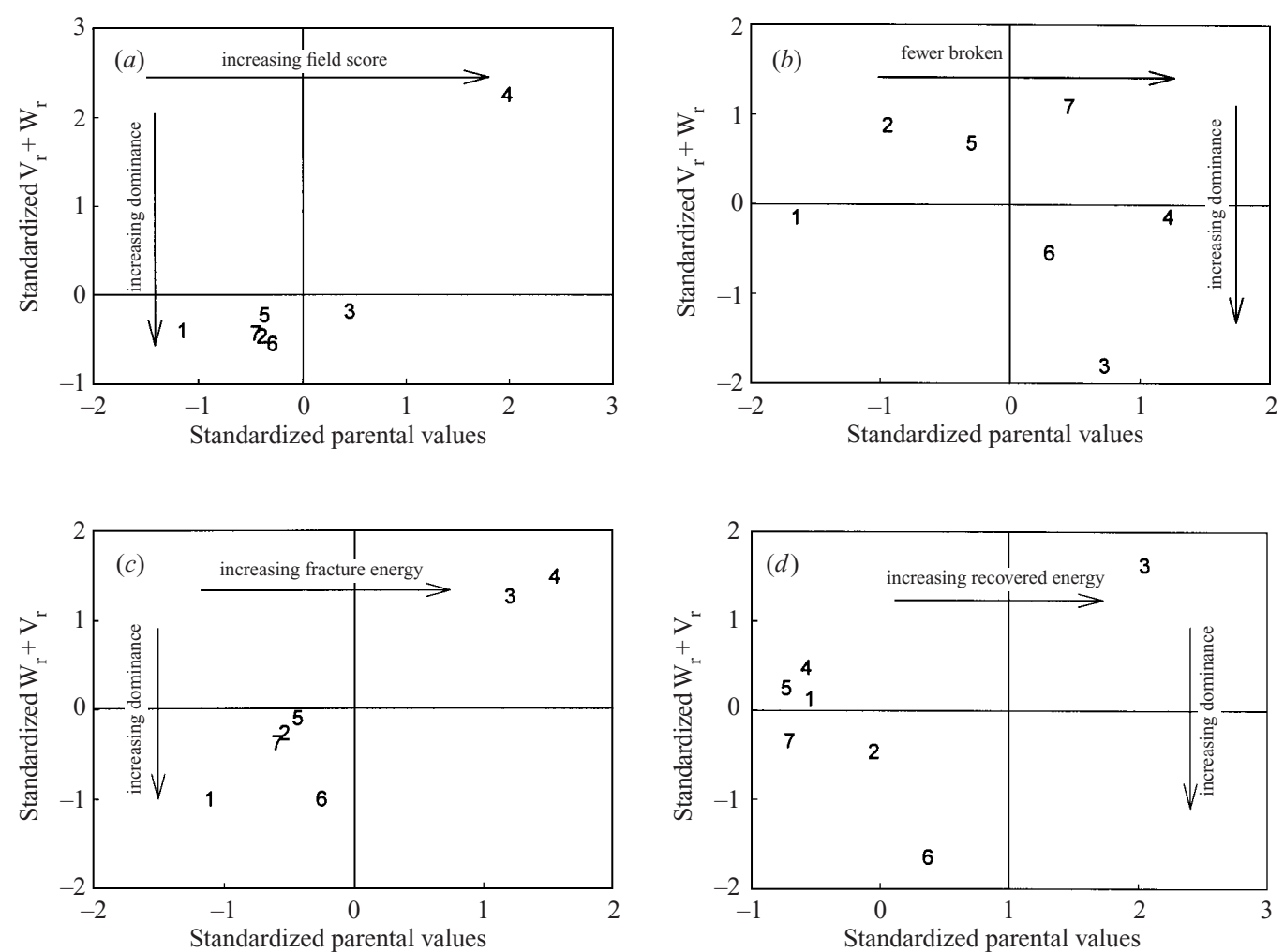

Fig. 3. Relationship of the phenotypic expression of a character to the extent of its genetic dominance. Points are standardized to the mean parental value using $(\overline{\mathrm{x}}-\mathrm{x}) / \sigma^{2}$. (a) Mean pod wall thickness; $(b)$ field pod shatter score; $(c)$ number of intact pods after $20 \mathrm{~s}$ random impact; $(d)$ pod fracture energy (tensile separation). Lines are: 1. q28; 2. z79; 3. dk129; 4. dk142; 5. dk150; 6. Apex; 7. Tapidor.

regression in the hybrid/mid-parent relationship differs most from 1 (Fig. 4d) indicating the importance of SCA in these results. The position of the hybrid values indicates that genes within z79 and dk142 confer greater pod compliance while those of $\mathrm{dk} 150$ confer greater rigidity. Elasticity of the cell wall was not calculated.

\section{Pod, raceme and plant characters}

Statistically there were significant block effects and family $\times$ block interactions for many of the pod, raceme and plant characters (Table 3, columns 2-4) though the values of the interaction mean squares were also small compared to those for the main family effects with a mean value of only $4 \%$ and thus, of little biological importance. Total variance was apportioned largely between error variance $\left(\sigma^{2}\right)$ and among family variance $\left(\sigma_{\text {family }}^{2}\right)$ with little variation resulting from either block effects or family $\times$ block interactions (Table 3, columns 5-8). Despite their significance block effects accounted for less than $5 \%$ while the average family $\times$ block interaction was only
$6 \%$ of the variation for all characters. All characters showed highly significant variation among families $\left(\sigma_{\text {family }}^{2}\right)$ with the proportion accounted for rising from $17 \cdot 3 \%$ for the number of primary branches to $61 \%$ for the number of seeds per pod.

In all cases but one, non-additive gene effects, as determined by the male $\times$ female interaction, were statistically highly significant (Table 4 ) though the mean squares were mostly much lower in magnitude than those of the combined male and female main effects $(7 \%$ on average). Exceptions were observed for stem thickness and the number of primary branches where these values rose to $34 \%$ and $55 \%$ respectively. There was significant variation among both male and female arrays though the relative magnitude of this variation varied between male and female arrays; thus for example, males showed greater variation for plant height and females greater variation for pod length. Overall levels of combining ability were high (66-80\%); however, stem thickness and the number of primary branches were very low $(<40 \%)$ with pod density and mean seed weight intermediate (c. $55 \%$ ). 

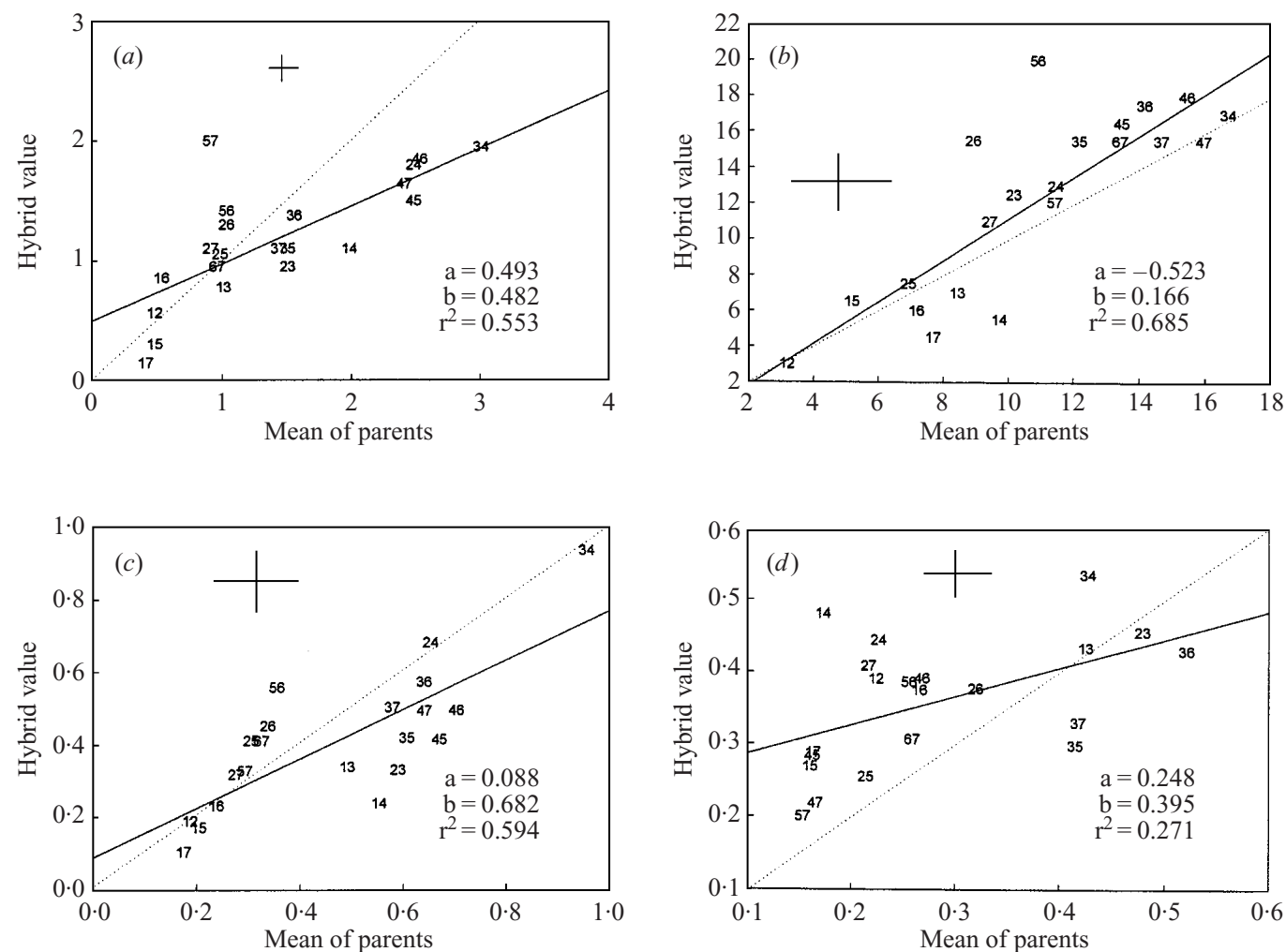

Fig. 4. Relationship between family (hybrid) means and the mean value of their parents. The slope of the line (b) indicates additivity of gene action such that $1=$ full additive gene action and $0=$ full dominance gene action. First number of each point is female parent; second number is male parent. Parents are: 1. q28; 2. z79; 3. dk129; 4. dk142; 5. dk150; 6. Apex; 7. Tapidor.

\section{DISCUSSION}

The characters described in detail above (but also including peak load) are the main ones used in this study to define the pod shattering resistance trait and each measured a different aspect of the character. They thus contribute different information needed to interpret and understand why some pods are more shatter resistant than others and how these differences are regulated.

These analyses of the pod shattering resistance trait show that the various measures of assessing the phenotypic expression of the character give different indications of the gene actions involved and that there are, therefore, likely to be several different, independent genes involved. Overall, additivity (Table 4) is much greater than non-additive gene effects; thus the force needed to initiate pod dehiscence (peak load) and the energy needed to extend the initial fracture (fracture energy) have non-additive components contributing less than $15 \%$ of additive gene effects (Table 4). In contrast recovered energy is regulated to a greater extent by dominant gene action
(66\% of addititive effects). Recovered energy, a measure of stored energy, derives from the shape and deformation of the valve and was related to the mean pod wall thickness and also the depth of the pod (this was a measure of the degree of 'cuppedness' and was highly correlated with the ratio of pod width to depth). Thus line dk129, which had the most compliant pods where the pod walls were the most elastic (recovered energy, 0.66 J), had the deepest and most thick walled pods (Table 2). Apex, with relatively thin walls and deep pods, and z79, with thicker walls and deep pods, showed less elasticity $(0.34 \mathrm{~J}$ and $0 \cdot 28 \mathrm{~J}$ respectively) while the remaining lines which generally had the thinnest walls and less deep pods (mean $=0.17 \mathrm{~J})$ were stiffest. Field score for pod shattering resistance, which is a measure of the resultant actions of all the other traits, was intermediate to these characters $(32 \%$ dominant gene effects) and appeared to behave as if resistance was controlled by recessive genes. In comparison, the number of pods remaining intact after $20 \mathrm{~s}$ in the random impact tests, which is an attempt to devise a laboratory test under controlled conditions mimicking 
the situation in the field, behaves in a largely additive manner suggesting that the forces acting during tactile bending of the pods in the field differ from the random impacts that arise from the ball bearings in the random impact tests. Dehiscence in the field occurs naturally at the pedicel end of the pod and then extends to the beak while it was noted that in the random impact tests the beak was often broken first thus allowing the initiation of dehiscence from both ends of the pod.

Of the plant, raceme and pod characters measured, only plant height, pod wall thickness and pod depth showed important correlations with the several measures of pod shattering resistance. Those relationships with the most important biological significance are described in Fig. 1. There were extremely close associations between field score and peak load and fracture energy (tensile separation tests) which were, in turn, less well associated with the pod measurements of wall thickness and depth (shape). The association of these three measures of pod shattering resistance was slightly lower with the number of intact pods at $20 \mathrm{~s}$ (random impact tests) which, however, showed no association with pod wall thickness and shape. This demonstrates that the tests are different in nature and measure different aspects of the resistance mechanisms. The energy recovered during tensile separation tests was strongly associated with the pod characters measured but only less well with fracture energy and peak load, again suggesting that pod architecture was only partly responsible for pod shattering resistance. There were many other statistically significant correlations which had low coefficients of determination $\left(r^{2}\right)$ and were of little biological importance in these tests, though perhaps some, like pod angle and pod length, would be significant in the crop canopy. The one exception to this was plant height and to a lesser extent beak length as also described by Morgan et al. (1998). It is possible that these are genetically linked characters which have no direct bearing on the shatter resistance of these lines. The associations may reflect similar origins from the diploid parents used to make the synthetic oilseed rape.

When considering the potential of pod shattering resistance in crop improvement, other pod characters are likely to be important in addition to those described above, as also are aspects of the crop canopy within the field situation. Though these characters are likely to be secondary in importance to the primary pod structure, it is important to consider their phenotypic effects and genetic control. For example, erect pods might be directly beneficial, resulting in a canopy in which the pods are 'protected' from damage by their closeness to the rachis; however, short pods with thick walls might give stronger pods but confer serious penalties in yield resulting from an increase in the dry matter of the pod walls. These must be weighed against the negative effects of correlations such that deleterious pleiotropic effects must be eliminated from the genome. The extent to which these characters can be manipulated depends also on the strength of their genetic control as well as on gene linkage and pleiotropy. There are strong correlations among those characters directly measuring aspects of pod shattering resistance but these are not, or are only loosely, correlated with the other morphological characters which might be expected to have a bearing on resistance. This suggests that gene linkage or pleiotropy are not likely to restrict the success of a breeding programme. Prospects for successful incorporation of the shatter resistance character through a breeding programme are enhanced by the strong heritabilities estimated for most of the characters. Within this diallel programme the degree of heritability was very high for most characters (Table 4) suggesting that it should be possible to combine and incorporate any of these characters into suitable genetic backgrounds for commercial purposes. However, introgressing such complex, recessive traits within a conventional breeding programme is difficult so the use of marker assisted technology within a breeding programme would be beneficial.

We would like to thank MAFF for the provision of grant no NF0306 and to Mr G. Gale for designing and building the device for measuring pod wall thickness.

\section{REFERENCES}

Davies, G. C. \& Bruce, D. M. (1997). Fracture mechanics of oilseed rape pods. Journal of Materials Science 32, $5895-5899$.

Genstat (1987). Genstat 5. Reference Manual. Statistics Dept., IACR, Rothamsted. Oxford: Clarendon Press.

HaYman, B. I. (1954). The analysis of variance of diallel tables. Biometrics 10, 235-244.

Kadkol, G. P., Macmillan, R. H., Burrow, R. P. \& Halloran, G. M. (1984). Evaluation of Brassica genotypes for resistance to shatter I. Development of a laboratory test. Euphytica 33, 63-73.
Ministry of Agriculture, Fisheries and Food (1997). UK Food and Farming in Figures. Government Statistical Service. London: The Stationery Office.

Morgan, C. L., Bruce, D. M., Child, R., Ladbrooke, Z. L. \& ArthuR, A. E. (1998). Genetic variation for pod shatter resistance among lines of oilseed rape developed from synthetic B. napus. Field Crops Research 58, 153-165.

PARKIN, I. A. P. (1995). Genetic analysis of the amphidiploid genome of Brassica napus. Ph.D. thesis, University of East Anglia. 
Petersen, M., Sander, L., Child, R. D., VanOnckelen, H. A., Ulviskov, P. \& Borkhardt, B. (1996). Isolation and characterisation of a pod dehiscence zone-specific polygalacturonase from Brassica napus. Plant Molecular Biology 31, 517-527.

Price, J. S., Hobson, R. N., Neale, M. A. \& Bruce, D. M.
(1996). Seed losses on commercial harvesting of oilseed rape. Journal of Agricultural Engineering Research 65, 183-191.

Thompson, K. F. \& Hughes, W. G. (1986). Breeding and varieties. In Oilseed Rape (Eds D. H. Scarisbrick \& R. W. Daniels), pp. 32-82. London: Collins. 